SHS Web of Conferences 24, 01007 (2016)

DOI: $10.1051 /$ shsconf/ 20162401007

C) Owned by the authors, published by EDP Sciences, 2016

\title{
Analysis of the development trend of China's business administration based on time series
}

\author{
Rui Jiang \\ Business School, Northwest Normal University, Lanzhou, Gansu, China
}

\begin{abstract}
On the general direction of the economic system, China is in a crucial period of the establishment of the modern enterprise system and reform of the macroeconomic system, and a lot of high-quality business administration talents are required to make China's economy be stably developed. This paper carries out time series analysis of the development situation of China's business administration major: on the whole, the society currently presents an upward trend on the demand for the business administration talents. With the gradually increasing demand for the business administration talents, various colleges and universities also set up the business administration major to train a large number of administration talents, thus leading to an upward trend for the academic focus on business administration.
\end{abstract}

Keywords: time series analysis; business administration; development trend

\section{INTRODUCTION}

At present, the business administration major is closely related to the development of social economy and forms a cutting-edge application-oriented discipline. In recent years, with gradual acceleration of the progress in the global economic integration, there is a more and more obvious difference between the supply and demand of the business administration talents. With more and more frequent economic relations with the trade between various countries, China's economic development gradually tends to be internationalized. Therefore, in the next period, China requires a lot of business administration talents ${ }^{[1-3]}$. On the general direction of the economic system, China is in a crucial period of the establishment of the modern enterprise system and reform of the macroeconomic system, and a lot of high-quality business administration talents are required to making China's economy be stably developed.

Since 1990, some researchers have begun to research the visualization application software and related implementation algorithm in the knowledge field in the teaching process of the business administration, creatively realizing an objective relation between the visualization technology of the business administration and scientific metrology. In 2004, some researchers developed a specialized scientific field and carried out classified application analysis toward the literature title, author, introduction, key words and topic on the industrial management direction by the use of CiteSpace software, thus this method gradually becomes a universally applicable law in the scientific metrology ${ }^{[4]}$.

In the Human Resources Guide, Dave Ulrich proposes that the human resources shall overcome several challenges: create an ability-oriented value chain which is integrated with globalization, competitiveness and human resource; reduce cost and rapidly increase profits; boast wide changes; attract and reserve competent talents; conduct improvement and transformation ${ }^{[5]}$. In the 21 st century, the human resource of the business administration goes through the impact of the global integration and information networks, knowledge and innovation, customer power, benefits of investors, organization speed and ability, force of change and various kinds of forces. The factors from all aspects gradually change and perfect the theoretical system of the business administration major ${ }^{[6]}$.

On the whole, the society currently presents an upward trend on the demand for the business administration talents. Meanwhile, in the next period, many Chinese enterprises are difficult to find the competent business administration talents. With the gradually increasing demand for the business administration 
Table 1. Contrast between the new and old business administration major

\begin{tabular}{ll||ll}
\hline 1202 & Business administration & 1102 & Business administration (part) \\
\hline & & 110201 & Business Administration \\
& & $110217 \mathrm{~S}$ & Business Planning Management \\
$120201 \mathrm{~K}$ & Business Administration & $110213 \mathrm{~S}$ & Franchise Management \\
& & $110207 \mathrm{~W}$ & Merchandising \\
& & $110214 \mathrm{~S}$ & Chain Business administration \\
120202 & Marketing & $110317 \mathrm{~S}$ & Food Economy Management \\
$120203 \mathrm{~K}$ & Accounting & 110202 & Marketing \\
120204 & Financial Management & 110203 & Accounting \\
120205 & International Business & 110204 & Financial Management \\
120206 & Human Resource Management & $110211 \mathrm{~W}$ & International Business \\
12027 & Auditing & 110205 & Human Resource Management \\
120208 & Asset Evaluation & $110208 \mathrm{~W}$ & Auditing \\
120209 & Property Management & 1102155 & Asset Evaluation \\
120210 & Cultural Industry Management & $110212 \mathrm{~S}$ & Property Management \\
\hline & $110310 \mathrm{~S}$ & Cultural Industry Management \\
\hline
\end{tabular}

talents, various colleges and universities also set up the business administration major to train a large number of administration talents, thus meeting the needs of market development. In this regard, the business administration major among colleges and universities is also reformed. The contrast between the new and old business administration major is shown in Table $1^{[7,8]}$.

Since the 1980s, enlarged recruitment is being promoted in China's higher education, thus the mode of higher education gradually is converted from the meritocracy to the public, the number of college students is increased year by year, and some colleges which are lack of teachers and appropriate hardware facilities even fell behind the pace of the era. From this, it's not difficult to see that the cultivation of the business administration talents under the higher education fails to be effectively guaranteed. Under this overall situation, appropriate adjustments and innovation must be made for training the undergraduate talents in the business administration, thus improving the training quality of the business administration talents in order to meet the needs of social development ${ }^{[9-11]}$.

\section{MODELING}

For the time series analysis, this paper lists the changes of events in accordance with the time sequence, thus constituting an analyzable time series. We carry out effective investigation and research on the time series in order to identify its corresponding changes and development rules and predict that its future trend is the corresponding time series analysis.

\subsection{Introduction to time series analysis ${ }^{[12-13]}$}

For the time series analysis, there is a need to first understand the following model:

(1) AR (p) model

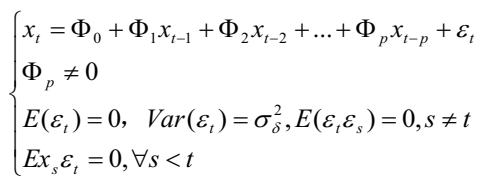

The model with the above structure is called as p-order autoregressive model. Here, it is recorded as AR (p).

(2) MA (q) model

$\left\{\begin{array}{l}x_{t}=u+\varepsilon_{t}-\theta_{1} \varepsilon_{t-1}-\theta_{2} \varepsilon_{t-2}-\ldots-\theta_{q} \varepsilon_{t-q} \\ \theta_{q} \neq 0 \\ E\left(\varepsilon_{t}\right)=0, \operatorname{Var}\left(\varepsilon_{t}\right)=\sigma_{\delta}^{2}, E\left(\varepsilon_{t} \varepsilon_{s}\right)=0, s \neq t\end{array}\right.$

The model with the above structure is called as q-order autoregressive model. Here, it is recorded as MA (q).

(3) ARMA (p, q) model

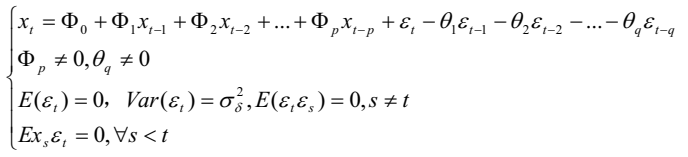

The model with the time series analysis of above structure is called as p-order autoregressive model or q-order autoregressive model. Here, it is recorded as $\operatorname{ARMA}(\mathrm{p}, \mathrm{q})$.

\subsubsection{Stationary sequence modeling}

(1) Modeling steps

The following process is listed according to the number of papers which is regarded as initial data and related to the business administration in the economic core journals from 2000 to 2014: the correlation coefficient calculation sample, the model is not, number of estimates, model test, model optimizing and series forecast, as shown in Figure 1. 


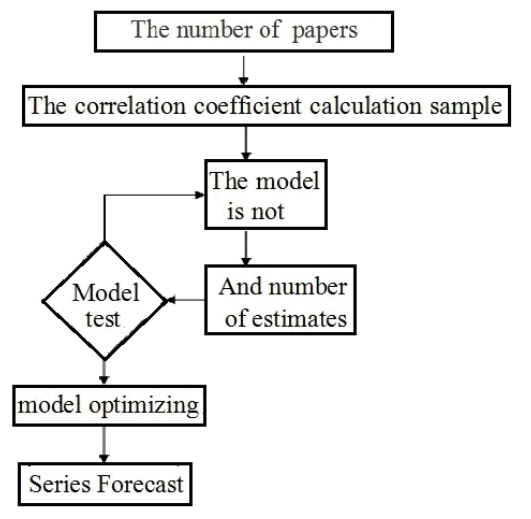

Figure 1. Stationary sequence modeling process

(2) Calculation of correlation coefficient of the sample

Sample autocorrelation coefficient is shown as follows:

$$
\hat{\rho}_{k}=\frac{\sum_{t=1}^{n-k}\left(x_{t}-\bar{x}\right)\left(x_{t+k}-\bar{x}\right)}{\sum_{t=1}^{n}\left(x_{t}-\bar{x}\right)^{2}}
$$

Partial autocorrelation coefficient (sample) is shown as follows:

$\hat{\Phi}_{k k}=\frac{\hat{D}_{k}}{\hat{D}}$

(3) Model recognition Basic principle is shown as follows:

\begin{tabular}{lll}
\hline$\hat{\rho}_{k}$ & $\hat{\Phi}_{k k}$ & Selection model \\
\hline Tailing & P-order tailing & $\operatorname{AR}(\mathrm{p})$ \\
Q-order tailing & Tailing & $\operatorname{MA}(\mathrm{q})$ \\
Tailing & Tailing & $\operatorname{ARMA}(\mathrm{p}, \mathrm{q})$ \\
\hline
\end{tabular}

(4) Approximate distribution of the sample correlation coefficient

Barlett:

$\hat{\rho}_{k} \sim N\left(0, \frac{1}{n}\right), n \rightarrow \infty$

Quenouille:

$\hat{\Phi}_{k k} \sim N\left(0, \frac{1}{n}\right), n \rightarrow \infty$

(5) Parameter estimation

The parameters to be estimated are $p+q+2$ un-

known parameters. The commonly used estimation methods are: moment estimation, maximum likelihood estimation and significance testing of six models.

Objective: Test the validation of the model (whether the extraction of information is adequate)
Testing object: residual sequence

Judging principle: A good fitting model should be able to extract the relevant information of the sample in the observed value sequence, that is, the residual sequence should be data to be discussed. On the contrary, it depends on the situation.

Null hypothesis: the number of volleyball papers in the sports core journals:

$H_{0}: \rho_{1}=\rho_{2}=\ldots=\rho_{m}=0, \forall m \geq 1$

Alternative hypothesis: The corresponding residual sequence is the data to be discussed:

$\mathrm{H}_{1}:$ At least, there exists $\rho_{\mathrm{k}} \neq 0, \forall \mathrm{m} \geqslant 1, \mathrm{k} \leqslant \mathrm{m}$

Test statistics:

LB statistics

$L B=n(n+2) \sum_{k=1}^{m}\left(\frac{\hat{\rho}_{k}^{2}}{n-k}\right) \sim \chi^{2}(m)$

Significance testing of the parameters:

Objective: Test whether each unknown parameter value is nonzero. Delete those insignificant parameters:

$$
H_{0}: \beta_{j}=0 \quad H_{1}: \beta_{j} \neq 0
$$

Test statistics:

$T=\sqrt{n-m} \frac{\hat{\beta}_{j}-\beta_{j}}{\sqrt{a_{i j} Q(\widetilde{\beta})}} \sim t(n-m)$

Model optimization

Problem posing: Here, we assume that the model passes the corresponding tests, indicating that if the data is within a certain feasible range, this model can effectively obtain the corresponding results.

Optimization purpose: Choose a relatively optimal model.

Series forecast

Linear prediction function is shown as follows:

$x_{t}=\sum_{i=0}^{\infty} C_{i} x_{t-1-i}$

Predict the minimum variance principle is shown as follows:

$\operatorname{Var}_{\hat{x}_{t(l)}}\left[e_{t}(l)\right]=\min \left\{\operatorname{Var}\left[e_{t}(l)\right]\right\}$

It is a factor of the further model analysis.

\subsubsection{Nonstationary sequence modeling}

We need to first conduct stationary operation for the data and then establish ARIMA (p, q) model to solve this process. Next, we will introduce this model.

The usage occasion of the model structure is the 
stationary series fitting of the difference:

Model structure is shown as follows:

$$
\left\{\begin{array}{l}
\Phi(B) \nabla^{d} x_{t}=\Theta(B) \varepsilon_{t} \\
E\left(\varepsilon_{t}\right)=0, \operatorname{Var}\left(\varepsilon_{t}\right)=\sigma_{\varepsilon}^{2}, E\left(\varepsilon_{t} \varepsilon_{s}\right)=0, s \neq t \\
E x_{s} \varepsilon_{t}=0, \forall s<t
\end{array}\right.
$$

Modeling steps: (observed sequence value obtained, stationary test, difference operation, variables test, fitting ARMA model, analysis result), as shown in Figure 2:

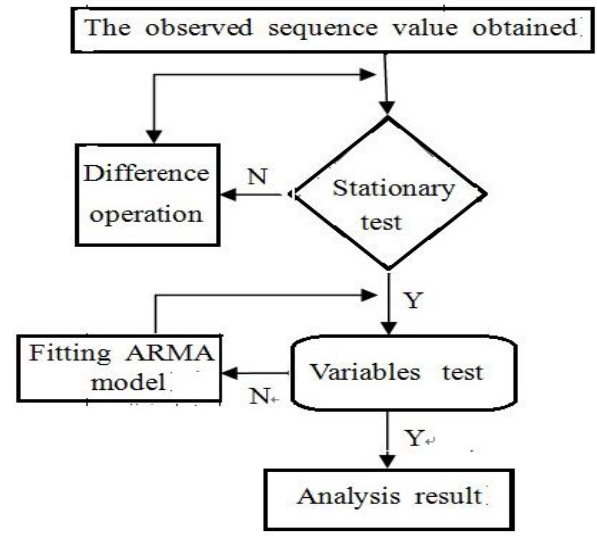

Figure 2. Nonstationary sequence modeling flowchart

\subsection{Model application and corresponding data processing}

For the cultivation of China's business administration talents, the management level includes junior managers, middle managers and senior managers; the positioning of the talent knowledge and ability includes the theory-oriented senior talents, practice-oriented applied talents and theoretical researchers; the employment positioning in the business administration major includes the enterprise, government's economic management departments and the teaching \& research institutions. For the above classification, the contemporary college students also have corresponding training positioning. The college students believe that the business administration personnel are distributed as Table 2.

For the above data, we analyze the item of the management level, and "black-white pie" diagram is shown in Figure 3:

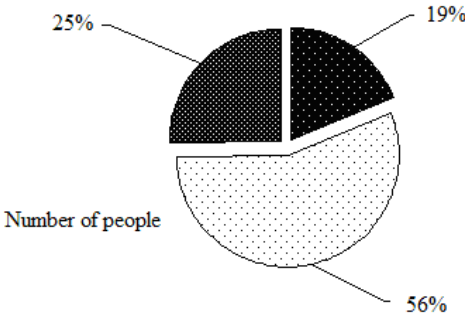

Figure 3. Classification of the proportion of college students' views

As can be seen from the above analysis, for the training of the business administration talents, the senior managers account for $56 \%$ of the total contemporary college students, while the junior managers and middle managers respectively account for $19 \%$ and $25 \%$.

According to keywords in the relevant papers related to the business administration listed in Table 3, the results are shown in the following table after conducting statistics about the related keywords from CNKI:

Table 3. Number of keywords

\begin{tabular}{ll||ll}
\hline Year & Number & Year & Number \\
\hline 2000 & 396 & 2007 & 294 \\
2001 & 540 & 2008 & 425 \\
2002 & 599 & 2009 & 473 \\
2003 & 524 & 2010 & 533 \\
2004 & 399 & 2011 & 628 \\
2005 & 427 & 2012 & 688 \\
2006 & 304 & 2013 & 735 \\
\hline
\end{tabular}

Based on the above data, "black and white bar chart" is shown in Figure 4:

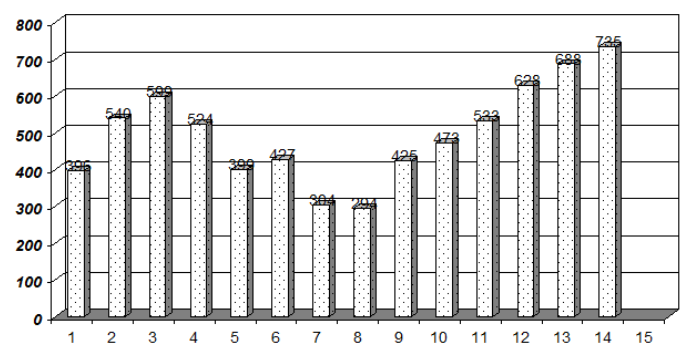

Figure 4. Variation trend of the number of keywords

Table 2. Business administration talents training (student's view)

\begin{tabular}{lll}
\hline Management-level & Positioning of the talent knowledge and ability & Employer positioning \\
\hline Senior managers $(56 \%)$ & Theory-oriented senior talents $(24.2 \%)$ & Enterprise $(21.2 \%)$ \\
Middle managers $(25 \%)$ & Practice-oriented applied talents $(66.7 \%)$ & $\begin{array}{l}\text { Government's economic management } \\
\text { departments }(24.2 \%)\end{array}$ \\
Junior managers $(19 \%)$ & Theoretical researchers $(9.16 \%)$ & Teaching \& research institutions $(6.1 \%)$ \\
& & Above units $(48.5 \%)$
\end{tabular}


The number of keywords can basically reflect the main idea of an article, the theme discussed, the methods used and important conclusions obtained. Therefore, rational analysis on the keywords in the business administration has important significance. As can be seen from the analysis on the variation trend of the keywords in the papers related to the business administration, the number of papers related to the business administration presents an upward trend in recent years.

The decomposition of the corresponding time series data shows a pink line of the tendency, a green line of the seasonal cycles, and a blue line of stochastic, as shown in Figure 5:

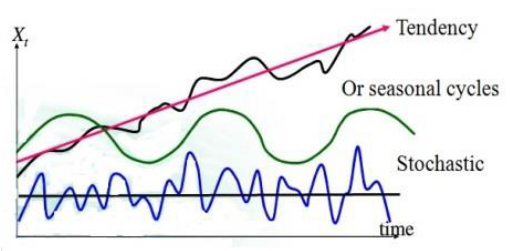

Figure 5. Decomposition of the time series data contrast figure

In order to more accurately grasp the development trend of the business administration major, the users in CNKI carry out statistical analysis of the focus on business administration. From 1997 to 2014, the results of the statistical analysis on the number of users focus are shown in Table 4:

Table 4. Number of users focus

\begin{tabular}{ll||lc}
\hline Year & Number & Year & Number \\
\hline 1997 & 255 & 2007 & 480 \\
1998 & 281 & 2008 & 497 \\
1999 & 265 & 2009 & 489 \\
2000 & 261 & 2010 & 533 \\
2001 & 275 & 2011 & 728 \\
2002 & 276 & 2012 & 748 \\
2003 & 296 & 2013 & 749 \\
2004 & 6 & 2014 & 789 \\
2005 & 406 & 2015 & - \\
2006 & 398 & - & - \\
\hline
\end{tabular}

Source: CNKI academic trends

The mode of higher education is gradually converted from the meritocracy to the public, the number of college students is increased year by year, and some colleges which are lack of teachers and appropriate hardware facilities fall behind the pace of the times, so the quality of the business administration talents trained under the higher education fails to be effectively guaranteed. Under this overall situation, appropriate adjustments and innovation must be made for the training of the undergraduate talents in the business administration, thus improving the training quality of the business administration talents in order to meet the needs of social development. Therefore, the social focus on business administration presents an upward trend, and its results are shown in Figure 6:

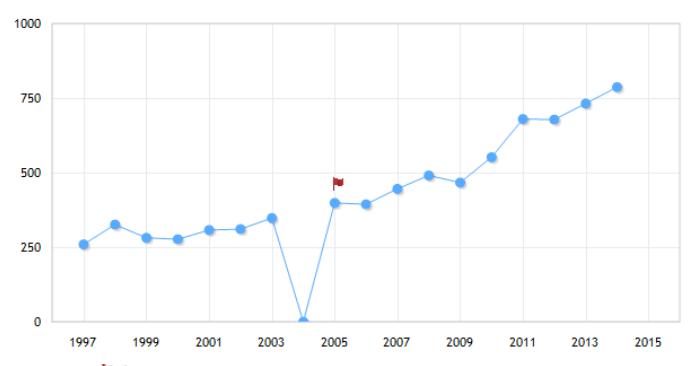

Note: indicates that the value of the identification point is higher than that of two points in front and back, and its growth rate is more than $30 \%$, compared with the previous value

Figure 6. Academic focus on the business administration

\section{CONCLUSION}

With more and more frequent economic relations with the trade between various countries, China's economic development gradually tends to be internationalized. Therefore, in the next period, China requires a lot of business administration talents. On the general direction of the economic system, China is in a crucial period of the establishment of the modern enterprise system and reform of the macroeconomic system, and a lot of high-quality business administration talents are required to make China's economy be a stable development. On the whole, the society currently presents an upward trend on the demand for the business administration talents. Meanwhile, in the next period, many Chinese enterprises are difficult to find the relevant competent business administration talents. With the gradual increase of the demand for the business administration talents, various colleges and universities also set up the business administration major to cultivate a large number of administration talents, thus meeting the needs of market development.

\section{REFERENCES}

[1] Qiao Chuanfu \& Qin Changcai. 2009. Research on China's development direction of Business Administration Major - Based on the perspective of curriculum provision. Consume Guide, 02: 134-135.

[2] Amel Kouaib \& Anis Jarboui. 2014. External audit quality and ownership structure: interaction and impact on earnings management of industrial and commercial Tunisian sectors. Journal of Economics, Finance and Administrative Science.

[3] M.M. Eissa. 2011. Demand side management program evaluation based on industrial and commercial field data. Energy Policy, 3910. 


\section{SHS Web of Conferences}

[4] Zou Zhaoying \& Qiu Yingming. 2009. Comparative Analysis of Business administration Personnel Training Mode. Human Resource Management, Z1: 80-82.

[5] Wang Li. 2014. Enterprise business administration status analysis and development thinking. Modern Economic Information, 07: 97.

[6] Anonymous. 2011. China Industrial Waste Management Commences Commercial Operations at Zhuorui Subsidiary. Manufacturing Close - Up.

[7] Terence Y.M. Lam. \& Henry K.H. Man. 2013. Economic and management perspectives on control of illegal land uses in the leasehold system. Property Management, 312 .

[8] Bai Jinfei. 2014. Enterprise business administration status analysis and discussion of development direction. Modern Business, 17: 162-163.

[9] Zhao Wei. 2014. Research and analysis of future development direction and management mode of enterprise business administration. Oriental Enterprise Culture, 17: 294.

[10] Xu Yihuan. 2015. Research and analysis of future development direction of enterprise business administration. Fortune Time, 10: 157.

[11] Hou Jianhua. 2009. Visual analysis of the evolution and research fronts of Business Administration. Dalian University of Technology.

[12] Liao Hua, Gao Yixuan \& He Lingyun. 2015. Conduction research on RMB exchange rate fluctuation on domestic price - analysis based on input-output time series table. Journal of Beijing Institute of Technology (Social Science), 03: 83-91.

[13] Fang Ziliang, Gao Jun \& Wang Junhui. 2003. Research on multi-factor time series method. Journal of Nanjing University of Science and Technology (Natural Science), 03: 298-300. 